\title{
Validly web-based dietary assessment questionnaire adapt- ed to evaluate eating patterns in American elementary school children
}

\author{
Ying Hua Gao-Balch* \\ Department of Human Science, University of Arkansas at Pine Bluff, Arkansas, USA
}

\begin{abstract}
Web-Based Dietary Assessment Questionnaire was developed as a surveillance instrument to measure dietary and physical activity behaviors in children and adolescents. This study was developed to evaluate the validity of food eating pattern from the elementary school version of the Web-Based Dietary Assessment Questionnaire. Validity was assessed by comparing food items selected on the questionnaire with food items reported from a single 24-hour recall covering the same reference period. To Identify and describe the major dietary eating patterns in the WT Cheney Elementary School and South Wood Elementary of the $4^{\text {th }}$ grade students in Pine Bluff Arkansas. Participants: Fourth-grade student volunteers ( $=87)$. Agreement between responses to Web-Based Dietary Assessment questionnaire items and reference values obtained through 24-hour dietary recall. Analysis the agreement between the questionnaire and the 24-hour recall was measured using Spearman correlation, percentage agreement, and kappa statistic. Correlation between Web-Based Dietary Assessment Questionnaire item responses and recall data ranged from .25 (bread and related products) to .67 (gravy). The percentage agreement ranged from $26 \%$ (bread and related products) to $90 \%$ (gravy). The kappa statistic varied from .06 (chocolate candy) to .60 (beans).Results from this study indicate that the Web-Based Dietary Assessment questionnaire can be administered in the classroom quickly and easily to measure many previous day dietary behaviors of fourth graders. However, questions addressing consumption of "vegetables," "candy," and "snacks" need further investigation
\end{abstract}

\section{Introduction}

The National Center for Health Statistics (NCHS) reports a third of American children are overweight, 70 percent of these children will become adults with body weight problems. Several studies have shown overweight children tend to be obese adults [1-3]; presently in the USA, studies show that a greater number of children are overweight and obese than any other race. In recent years, findings have presented important insights into issues surrounding overweight and obesity in African-American children in the United States. The latest data reveals that overweight and obesity issues among AfricanAmerican children have consistently remained neglected and underresearched [4]. The research have been specifically focus on eating patterns in populations of African-American children located in Pine Bluff, Arkansas.

What are the factors that make children at risk of becoming overweight or obese in adulthood? There are many factors in a child's life that can cause overweight and obesity. Current studies show that $20.5 \%$ of African-American children between the ages of 6 to 19 years old are overweight. Studies also show that $70.7 \%$ of African-Americans over the age of 20 years old are overweight and $39.4 \%$ are obese. The risk of obesity in children may be increased with an unhealthy dietary pattern [5]. Dietary patterns that are developed in childhood are most often carried into adolescence and adulthood [6]. Several studies have shown that school nutrition and physical education programs are factors that can address the risks of becoming overweight or obese [713].

What is the best prevention for becoming overweight or obese? Nutrition education and dietary behavior interventions in any combination of educational strategies, accompanied by environmental supports designed to facilitate voluntary adoption of food choices and other food- and nutrition-related behaviors conducive to health and well-being are effective in the prevention of overweight and obesity. Standardization of dietary assessment tools is needed for the collection of comprehensive dietary data that can help targeted dietary behavior interventions and provide additional endpoints by which to assess the efficiency of nutrition education and dietary behavior intervention. Further, a dietary monitoring tool needs to be adopted by a communitybased or school organization to become part of the standard practice of nutrition education in order to reach wider audience of individuals.

There are currently several dietary assessment tools available. Dietary behavior questionnaires are the most common dietary monitoring tool, as they are cost effective method and ideal for large sample sizes. Most researchers use questionnaires for gathering data and analysis. Researchers often use paper-based questionnaires which may delay response times and reduce response rates. Additionally, building questionnaires and analyzing the gathered paper based data can be difficult tasks for researchers. Web-based questionnaires are

Correspondence to: Ying Hua Gao-Balch, Ph.D., RDN, Department of Human Science, University of Arkansas at Pine Bluff, 1200 North University Drive, Pine Bluff, Arkansas 71601, USA, E-mail: gaobalchy@uapb.edu

Key words: web-based dietary assessment questionnaire, validation, elementary school

Received: January 25, 2015; Accepted: February 13, 2015; Published: February 16,2015 
becoming more popular and can provide a variety of options for researchers to create a fast and easy instrument to increase response times and rates.

\section{Approach and research procedures}

Commonly used dietary assessment tools include dietary history, seven-day recall, seven-day record, and food frequency questionnaires for assessing habitual food intake [14-20]. These tools are lengthy, difficult, and expensive to analyze. This project proposes to focus on a new method that will yield a precise and accurate measurement of dietary behavior that can simply and quickly identify food intake patterns of elementary school children.

This research was developed as a dietary behavior questionnaire system, with the support of UAPB's technical services that enables the rapid creation of web-based questionnaire web application. Development of the questionnaire was included web application development issues of data consistency, design security, performance and stability. A well-structured system was produced for online implementation. A comprehensive system for validating data testing strategy was be applied in the system testing and evaluation process.

We established a unique questionnaire to measure previous daily dietary behaviors that are to be useful as a monitoring tool based in standard dietary guidelines. This tool given to the child several times over a period of time will furthermore provide the potential to help in the assessment of eating habits elementary- school children. The questionnaire can be used in nutrition education and behavior adjustment programs. The questionnaire design was documented and evaluated to provide data for future nutrition education and dietary behavior intervention programs.

\section{Participants and setting}

To Identify and describe the major dietary eating patterns in the WT Cheney Elementary School and South Wood Elementary of the $4^{\text {th }}$ grade students in Pine Bluff Arkansas. Participants: Fourth-grade student volunteers $(\mathrm{N}=87)$.

\section{Method}

At each school, the students completed the web-based questionnaire in the morning, followed by a 24-hour dietary recall interview at least 2 hours later. The 24 hour dietary recalled and webbased questionnaire was administered by research staff to the students during school day and was coordinated for the convenience of the classroom teacher. Data collection during the school day is followed because dietary habits tend to vary on weekends more than weekdays. In addition, data not be collected on the day following a holiday. A typically, two research assistants went to the school to start the webbased questionnaires for foods consumed the previous day, and then begin individual 24-hour recalls with face-to- face interviews. Five students was participate in the study per day. A 24-hour recall tool was also include the use of disposable cameras to photograph the eating patterns of the participants. The team members were coordinates with the school officials and select participant students.

Students were given a disposable camera with specific simple instructions: to take a picture of what they ate or drank, including snacks. Team member's developed protocols to ensure the accuracy of the food intake photographed during the 24-hour period. Accuracy may include taking "before and after" photographs of a meal. The disposable cameras was collected the next day and taken for processing.
The photos were processed onto a compact disc to be viewed on a computer during the face-to-face interview. The photographs assist the child in recall of the meals and assist the team member with the interview. The photographs and the interviews was used to validate calories consumed, food combinations, and portion sizes, and amount of fat, carbohydrates, and proteins.

\section{Data analysis}

The web-based questionnaires were examined for multiple marking or other discrepancies that could invalidate the data for the purpose of the study. The project was used the Statistical Package for the Social Sciences (SPSS) format for data analysis.

The 24-hour dietary recall reports were edited after the recall. The previous day's school lunch and breakfast menus and portion size was obtained from the school food service to facilitate editing of the data. For example, if the student does not know the type of milk they consumed for lunch, the menu was providing those specifics. The 24-hour dietary recall data entered was obtained for each student and grouped into food categories to match the food items in the webbased questionnaire survey. For example, all the vegetables reported as consumed are matched to the web-based questionnaire survey vegetable consumption question. Food items that were not an exact match with the web-based questionnaire food categories was coded, after review, by a panel of two trained nutrition professionals. Most of these food items include mixed dishes containing meat, pasta, and vegetables that can be matched with questions pertaining to consumption of meat, pasta, and vegetables, respectively.

Analyses of the data conducted to test for agreement between the responses to food questions in the web-based survey and food items recorded and photographed during the 24 hour recall. For each foodrelated, web-based questionnaire evaluated, three separate analyses will be conducted; to assess data validity; correlations; percentage agreement; and weighted kappa statistic. The kappa statistic (Unweight) was used for the yes/no response items. Example: "Yesterday, did you eat breakfast?" and "yesterday, did you take a vitamin pill?" Data was analyzed using Statistical Package for the Social Sciences version 12.0 (SPSS, Inc. Chicago, IL, 2003) and Statistical Analysis System 8.0 for Windows (SAS) Institute, Cary, NC, 1999).

\section{Results}

The study sample consisted of 87 students, $47 \%$ boys and $53 \%$ girls, with ages ranging from 9 to 11 years and a mean of 10.31 years (SD \pm 0.5 ). Ethnicity, as reported by the students, was primarily "Black or African American" (99\%), Students took approximately 25-35 minutes to complete the survey and 20-30 minutes to complete the 24 -hour dietary recall interview.

\section{Spearman correlation}

Correlation between food items recoded on the 24-hour recall and Web-Based Dietary Assessment Questionnaire responses and their confidence intervals are reported in the Table. Correlation coefficients ranged from 0.12 for chocolate candy to 0.68 for gravy. Correlation coefficients for questions on consumption of French fries or any chips and consumption of gravy were different between girls and boys. In both cases, the correlation coefficient was higher for girls $(r=0.84$ for consumption of gravy, $r=0.77$ for consumption of French fries or any chips) than boys ( $r=0.49$ for consumption of gravy, $r=0.32$ for consumption of French fries or any chips) (Table 1). 
Table 1. Association between Questionnaire Responses and Items Recorded from Recall ${ }^{* \dagger}$

\begin{tabular}{|c|c|c|c|}
\hline Food Items & Total $r(95 \%$ CI $)$ & $\begin{array}{c}\text { Total kappa } \\
(95 \% \text { CI })\end{array}$ & $\begin{array}{c}\text { Total } \\
\text { Agreement } \\
(\%)\end{array}$ \\
\hline Gravy on food or by itself (Q9) & $0.68(0.55,0.77)$ & $.57(.34, .78)$ & 91 \\
\hline Beans (all except green beans) (Q19) & $0.67(0.54,0.77)$ & $.61(.43, .79)$ & 88 \\
\hline $\begin{array}{l}\text { Yogurt or cottage cheese or a yogurt } \\
\text { drink (Q13) }\end{array}$ & $0.32(0.17,0.49)$ & $.12(.08, .29)$ & 83 \\
\hline Peanuts or peanut butter (Q10) & $0.43(0.27,0.57)$ & $.34(.14, .49)$ & 79 \\
\hline Hot or cold cereal (Q16) & $0.68(0.55,0.75)$ & $.559 .43, .67)$ & 76 \\
\hline Frozen desserts (Q24) & $0.48(0.32,0.61)$ & $.32(.17, .48)$ & 75 \\
\hline $\begin{array}{l}\text { Fried meats: chicken, beef, pork, } \\
\text { fish (Q8) }\end{array}$ & $0.44(0.27,0.58)$ & $.39(.24, .55)$ & 72 \\
\hline $100 \%$ fruit juice $(\mathrm{Q} 21)$ & $0.46(0.30,0.59)$ & $.41(.28, .55)$ & 65 \\
\hline $\begin{array}{l}\text { Rice, macaroni, spaghetti, or pasta } \\
\text { noodles (Q14) }\end{array}$ & $0.65(0.51,0.75)$ & $.46(.34, .59)$ & 64 \\
\hline $\begin{array}{l}\text { Milk, all flavors, \& with other food/ } \\
\text { drinks (Q12) }\end{array}$ & $0.55(0.42,0.67)$ & $.49(.35, .62)$ & 56 \\
\hline French fries or any chips (Q17) & $0.57(0.43,0.68)$ & $.45(.32, .56)$ & 60 \\
\hline Sodas or soft drinks (Q23) & $0.53(0.38,0.64)$ & $.37(.24, .51)$ & 53 \\
\hline $\begin{array}{l}\text { Cheese alone, on pizza, or in dishes } \\
\text { (Q11) }\end{array}$ & $0.47(0.35,0.65)$ & $.31(.19, .44)$ & 46 \\
\hline $\begin{array}{l}\text { Fruit flavored drinks \& sports drinks } \\
\text { (Q22) }\end{array}$ & $0.42(0.25,0.56)$ & $.28(.16, .39)$ & 53 \\
\hline Fruit (Q20) & $0.41(0.24,0.56)$ & $.28(.16, .39)$ & 51 \\
\hline $\begin{array}{l}\text { Sweet, high-fat baked products } \\
\text { (Q25) }\end{array}$ & $0.38(0.21,0.53)$ & $.25(.12, .38)$ & 57 \\
\hline Red meats (Q7) & $0.38(0.25,0.52)$ & $.25(.13, .39)$ & 40 \\
\hline $\begin{array}{l}\text { Vegetables, including salads and } \\
\text { potatoes (Q18) }\end{array}$ & $0.35(0.17,0.54)$ & $.18(.055, .29)$ & 27 \\
\hline $\begin{array}{l}\text { Bread, bun, bagel, tortilla, or roll } \\
\text { (Q15) }\end{array}$ & $0.29(0.11,0.52)$ & $.14(.09, .28)$ & 25 \\
\hline Chocolate candy (Q26) & $0.12(-0.08,0.300)$ & $.061(-.08, .19)$ & 48 \\
\hline \multicolumn{4}{|l|}{ Other behaviors } \\
\hline Ate breakfast (Q27) & $0.75(0.64,0.89)$ & $.72(.53, .91)$ & 94 \\
\hline Number of meals (Q28) & $0.66(0.55,0.78)$ & $.48(.31, .65)$ & 85 \\
\hline Number of snacks (Q29) & $0.16(-0.03,0.34)$ & $.09(-.07, .21)$ & 38 \\
\hline Vitamin pill (Q30) & $0.53(0.34,0.59)$ & $.52(.35, .69)$ & 80 \\
\hline
\end{tabular}

*Food items and other behaviors are listed in order of decreasing correlation $(r)$. †Titles for food items are condensed from the wording of questionnaire items. For example, data reported in "Red meats" are from "Yesterday, did you eat hamburger meats, hot dogs, sausage (chorizo), steak, ribs?"

\section{Kappa statistics}

The kappa statistic values were shown in the Table 1. The kappa statistic values also covered a wide range, from .06 for chocolate candy to .60 for beans. Items addressing consumption of gravy, hot or cold cereal, and beans showed agreement above .5. Confidence intervals of the kappa statistic indicated that there was no significant difference between boys and girls for all the food items except gravy and french fries or any chips. Girls showed higher agreement (kappa $=.85$ for consumption of gravy, kappa $=.63$ for consumption of french fries or any chips) compared to boys (kappa $=.36$ for consumption of gravy, kappa $=.20$ for consumption of french fries or any chips). All 3 testspercentage agreement, Spearman correlation, and kappa statisticsshowed similar results.

\section{Percentage agreement}

The percentage agreement between food items recorded on the 24-hour recall and web-based questionnaire responses is shown in the Table. Food items recoded on the 24-hour recalls had a wide range of agreement, from low for bread, bun, bagel, tortilla, or roll (26\%) to high for gravy (90\%) when compared with responses on the web-bases questionnaire. The questionnaire report of having a snack showed low agreement (39\%) with the criterion value. There was a gender difference in agreement for the questions on consumption of gravy and consumption of french fries or any chips, indicating questionnaire agreement with recall data was better among girls $(97 \%$ for consumption of gravy, $71 \%$ for consumption of french fries or any chips) than boys ( $83 \%$ for consumption of gravy, $48 \%$ for consumption of french fries or any chips) for these 2 items.

\section{Discussion}

This study examined the validity and reliability of a revised webbased food questionnaire measure, This was important given the need for valid and easy to elementary school students measures of beliefs and attitudes towards food.

The validity of a web-based questionnaire is the degree to which the instrument measures the dietary intake of the subjects it was designed to study. Studies of the validity of a web-bases food questionnaire are often difficult to carry out owing to the problems in obtaining a sufficiently large and representative sample of the population to which web-bases questionnaire may be applied. The web-bases questionnaire uses a no quantified food frequency approach to assess the previous day's food consumption in which the frequency of consumption of food items is noted without the portion sizes. Hence, students should know the food items that they ate and the number of times they ate each food item during that day.

To our knowledge, there is no agreement in the research as to tested whether the validity of dietary assessment tools by the best statistical method [21], though it is essential to use more than one statistical method to provide credence to the results [22,23]. The frequently used method of assessing agreement in ranking between a web-bases food frequency questionnaire and the 24-hour dietary recall is Spearman rank correlation for data with non-normal distribution. Other indicators of agreement include percentage agreement and kappa statistic.

Criterion measures, used for validation, should be precise, and errors resulting from one method should be independent of the other method [24]. The study population was fourth-grade students (aged 9-11 years); hence, a 24-hour recall was selected as the criterion method to overcome the difficulties associated with the literacy and motivational levels. Although the intra-individual variability in diet excludes the use of a single recall as an accurate representation of individual dietary intake, the recalls provide a valid assessment of group level mean intake [25]. Several studies support the validity of this method in school-aged children $[26,27]$.

Individual food-related question responses were compared with the responses obtained from a 24-hour recall where both the testing and the criterion methods covered the same dietary intake period. Values of kappa $\geq .75$ indicate almost perfect agreement, .45 to $<.75$ indicate substantial agreement, .20 to $<.45$ moderate agreement, .00 to $<.20$ fair agreement, and $<.00$ poor agreement [28]. Well-defined food items and food items consumed less frequently had higher validation scores compared to food in mixed dishes using all 3 methods of validation. For example, gravy, a single food item, had $90 \%$ agreement, a kappa $=.56$, and $r=0.67$. Less frequently consumed food, such as beans, had $88 \%$ agreement, kappa $=.60$, and $r=0.60$.

The poor agreement found for vegetables, assessed as a food group 
or as individual foods, was also reported by studies in the United States [29], Guatemala [30], China [31] (miners), and France [32] (nursing staff), but not by others, i.e., Mali [33], Japan [34], Sweden [35] (population based), and Finland [36] (pregnant women). Nevertheless, Cade et al. [37] noted in their review of validation studies for food questionnaire and reference methods are usually lowest for vegetables, explaining that misreporting of vegetables can occur for a number of reasons including double counting of items and social desirability bias. For the other foods with poor agreement, the results from other studies are more varied.

For questions addressing intake of vegetables, milk, and cheese (percentage agreement $27 \%$ to $46 \%$ ). These lower scores may be because these food items were consumed most of the time as a part of a mixed dish, such as cheese on pizza or milk on cereal. For example, $90 \%$ of the students responded in both the questionnaire and the recall that they consumed milk. But discrepancies were still observed in the frequency of milk consumption between the 2 assessment methods. This finding may be because milk served as a beverage was easier for the child to remember. But the child may have selected cereal on the questionnaire but then forgot to count the milk on cereal as another serving of milk, thus this item produced low validity. Further, pizza is such a commonly consumed food in schools that it may be useful to add a question on pizza intake to the questionnaire to prevent the child from having to break down this mixed food into its components. Also, these food behavior questions showed a low reliability compared to other food behavior questions [38].

Fruit and fruit juice consumption showed a similar result in eighthgrade students compared to the fourth-grade students, but validation measures for vegetables were lower. These lower scores may be because the younger students have difficulty in reporting vegetables in mixed food items. Also, the intake of fruit and fruit juice was quite low (number of times per day), with a median intake of "none" for yesterday and a mean of 1.32 times for yesterday, respectively. A similar pattern was observed in inner-city fourth- to seventh-grade children [39].

Questions related to meal pattern, such as "Yesterday, did you have breakfast?' or "Yesterday, how many meals did you eat?" tended to have acceptable validity, but the question, "Yesterday, did you have a snack?" had a poor validity. In the criterion measure (24-hour dietary recall), anything other than water that was consumed between meals was coded as a snack, but the child may have difficulty in differentiating a snack from a meal or may not remember consuming a snack without prompts when they are filling out the questionnaire. The question, "Yesterday, did you take a vitamin pill?" showed acceptable validity.

Most of the food questions showed no gender difference in validity. But for the questions regarding the consumption of gravy and french fries or any chips, girls showed a significantly higher validity than boys. This finding may be because boys over reported their frequency of intake in the survey. In contrast, Caution is necessary when comparing the kappa statistic with other studies because it is influenced by the number of categories involved [40].

Agreement in the estimation of absolute intake was assessed in the limits of agreement analysis. Key findings were that on average the web-bases questionnaire overestimated the intake of most foods, which was also reported in other validation studies [30,36,37], with large overestimations for intake of the fruit and vegetable groups. This is reflected also at the individual level, with 4 of the 37 food groups having $95 \%$ lower limits $\leq 0.05$, and 12 having upper limits $>20$; there were very broad ranges for many foods, but a general trend for overestimation.
The differences between the web-based questionnaire and 24 hours recall intake estimates varied significantly with magnitude of intake estimates for 14 food groups, with 9 showing a negative association and 5 showing a positive association. There was no clear pattern concerning which food groups had a negative, positive, or no association with magnitude of intake.

The poor performance of vegetables across measures of agreement is a matter of particular concern because of our interest in examining their potential role in overweight and obesity by. For all vegetable groups, intakes were estimated by web-based questionnaire. Correlations were modest, ranging from 0.08 to 0.40 , and were generally stronger for fruits. This is consistent with other studies in which levels of agreement between the web-based questionnaire and other dietary assessment methods were generally found to be poor for vegetables and fruits [41]. Reasons for this are not well established.

The multivariable modeling in the limits of agreement analysis shows that the models for fats and oils, poultry, seafood, various vegetable groups, rice, pasta and noodles, and all cereals and products explained $\geq 25 \%$ of the variation in difference between web-bases questionnaires and 24 hours recall. Of the other food groups with particularly poor performance, the model explained $\sim 10 \%$ of the variation in difference.

These findings have important implications for modeling dietobesity relations. The significant association between personal characteristics and difference for most food groups raises the possibility of differential bias and misclassification. Adjusting intake estimates for these characteristics will improve the validity of the model. One might expect this to be particularly appropriate for the vegetable groups, for which the performance of the web-bases questionnaire is otherwise poor, and a reasonably large proportion of variation in difference is explained by the models. This would also suggest that different subgroups of the study population may need different FFQ to accurately measure dietary intake; this remains to be confirmed by further investigation.

This is the first study we know of that directly assessed the association between personal characteristics and measurement errors in web-bases food intake estimates. It is widely acknowledged that a number of factors such as gender, age, and socioeconomic factors may be associated with the validity of dietary estimates [42]. Of all the personal characteristics studied, sex was most commonly associated with intake estimate errors for food groups; the presence of a medical condition and dietary supplement intake were also associated for some food groups. The findings highlight the need to assess web-bases questionnaire validity in a sample that is representative of the overall population in which the web-bases questionnaires will be used, with a sample size that is large enough to assess differences among subgroups.

\section{Acknowledgment}

This study was the sponsoring Institution of Arkansas State Agricultural Experiment Station.

\section{References}

1. Ferrao KF, Thrope RJ, Wilkinson JA (2003) The life course of severe obesity: does childhood overweight matter? J Gerontol B psycho Scisoc Sci 58: S110-S119. [Crossref]

2. Magarey AM, Daniels LA, Boulton TJ, Cockington RA (2003) Predicting obesity in early adulthood from childhood and parental obesity. Int J Obes 27: 500-513. [Crossref]

3. Must A (2003) Does overweight in childhood have an impact on adult health? Nutr Rev 61: 139-142. [Crossref] 
4. Amina PA, Hamisu MS, Thomas J, Berrings M, Donaldson G, et al. (2006) Obesity Research and the Forgotten African American Child. Ethnicity \& Disease 16: 2.

5. Nicklas TA, Yang S, Baranowski T, Zakeri I, Berenson G (2003) Eating patterns and obesity in children. Am J Prev Med 25: 9-16. [Crossref]

6. Nader PR, Stone EJ, Lytle LA (1999) Three-year maintenance of improved diet and physical activity: the CATCH Cohort. Arch pediatr Adolesc Med 153: 695-704. [Crossref]

7. Davison KK, Birch LL (2001) Childhood overweight: a contextual model and recommendations for future research. Obes Rev 2: 159-171. [Crossref]

8. United States General Accounting Office. Report to Congressional Register. Schoo Lunch program: efforts needed to improve nutrition and encourage healthy eating. Available at: www.gao.gov. Accessed on: 4/11/05.

9. Center for Science in the Public Interest. Dispensing junk: how school vending undermines Efforts to feed children well. Available at: www.cspinet.org. Accessed on: $5 / 2 / 05(9)$.

10. Kubik MY, Lytle LA, Hannan PJ, Story M (2003) The association of the school food environment with dietary behaviors of young adolescents. Am J Public Health 93 : 1168-1173. [Crossref]

11. Department of Health and Human Services, United States Department of Agriculture. Dietary guidelines for Americans 2005. Available at: www.health.gov. Accessed on: $4 / 23 / 05$.

12. National Institute of Child Health and Human Development Study of Early Child Care and Youth Development Network (2003) Frequency and intensity of activity of third grade children in physical education. ArchPediatric Adolescent Med 157:185-190.

13. Simons-Morton BG, Taylor WC, Snider SA, Huang IW

14. Beaton GH, Milner J, Corey P, McGuire V, Cousins M, et al. (1979) Sources of variance in 24-hour dietary recall data: implications for nutrition study design and interpretation. Am J ClinNutr 32: 2546-2549. [Crossref]

15. Block G, Hartman AM, Dresser CM, Carroll MD, Gannon J et al. (1986) A data-base approach to diet questionnaire design and testing. Am J Epidemiol 124: 453-469. [Crossref]

16. Briefel RR, Flegal KM, Winn DM, Loria CM, Johnson CL, et al. (1992) Assessing the nation's diet: limitations of the food frequency questionnaire. J Am Diet Assoc 92 : 959-962. [Crossref]

17. Hankin JH, Nomura AM, Lee J, Hirohata T, Kolonel LN (1983) Reproducibility of a diet history questionnaire in a case-control study of breast cancer. Am J ClinNutr 37: 981-985. [Crossref]

18. Neuhouser ML, Kristal AR, McLerran D, Patterson RE, Atkinson J (1999) Validity of short food frequency questionnaires used in cancer chemoprevention trials: results from the Prostate Cancer Prevention Trial. Cancer Epidemiol Biomarkers Prev 8: 721-725. [Crossref]

19. Olendzki B, Hurley TG, Hebert JR, Ellis S, Merriam PA, et al. (1999) Comparing food intake using the Dietary Risk Assessment with multiple 24-hour dietary recalls and the 7-Day Dietary Recall. J Am Diet Assoc 99: 1433-1439. [Crossref] 20. Gersovitz M, Madden JP, Smiciklas-Wright H (1978) Validity of the 24- hr. dietary recall and sevenday record for group comparisons. J Am Diet Assoc 73: 48-55. [Crossref]

20. Burema J, van Staveren WA, Feunekes GIJ (1995) Guidelines for reports on validation studies. Eur J ClinNutr 49: 932-933.

21. Burley V, Cade JB, Margetts R, Thompson, Warm D (2000) Consensus document on the development, validation and utilisation of food frequency questionnaires, Ministry of Agriculture, Fisheries and Food, London, UK.

22. Masson LF, McNeill G, Tomany JO, Simpson JA, Peace HS, et al. (2003) Statistica approaches for assessing the relative validity of a food-frequency questionnaire: use of correlation coefficients and the kappa statistic. Public Health Nutr 6: 313-321. [Crossref]
23. Willett W (1998) Nutritional Epidemiology (2nd ed.), Oxford University Press, New York.

24. McPherson RS, Hoelscher DM, Alexander M, Scanlon KS, Serdula MK (2000) Dietary assessment methods among school-aged children: validity and reliability. Prev Med 31: S11-S13.

25. Emmons L, Hayes M (1973) Accuracy of 24-hr. recalls of young children. J Am Diet Assoc 62: 409-416. [Crossref]

26. Lytle LA, Murray DM, Perry CL, Eldridge AL (1998) Validating fourth-grade students self-report of dietary intake: results from the 5 A Day Power plus Program. $J$ Am Diet Assoc 98: 570-572. [Crossref]

27. Munoz SR, Bangdiwala SI (1997) Interpretation of kappa and B statistics measures of agreement. J Appl Stat 24: 105-111.

28. Salvini S, Hunter DJ, Sampson L, Stampfer MJ, Colditz GA, et al. (1989) Food-based validation of a dietary questionnaire: the effects of week-to-week variation in food consumption. Int J Epidemiol 18: 858-867. [Crossref]

29. Torheim LE, Barikmo I, Hatloy A, Diakite M, Solvoll K, et al. (2001) Validation of a quantitative food-frequency questionnaire for use in Western Mali. Public Health Nutr 4: 1267-1277. [Crossref]

30. Rodriguez MM, Mendez H, Torun B, Schroeder D, Stein AD (2002) Validation of a semi-quantitative food-frequency questionnaire for use among adults in Guatemala. Public Health Nutr 5: 691-699. [Crossref]

31. Ogawa K, Tsubono Y, Nishino Y, Watanabe Y, Ohkubo T, et al. (2003) Validation of a food-frequency questionnaire for cohort studies in rural Japan. Public Health Nutr 6 : 147-157. [Crossref]

32. Forman MR, Zhang J, Nebeling L, Yao SX, Slesinski MJ, et al. (1999) Relative validity of a food frequency questionnaire among tin miners in China: 1992/93 and 1995/96 diet validation studies. Public Health Nutr 2: 301-315. [Crossref]

33. Bonifacj C, Gerber M, Scali J, Daures JP (1997) Comparison of dietary assessment methods in a southern French population: use of weighed records, estimated-diet records and a food-frequency questionnaire. Eur J Clin Nutr 51: 217-231. [Crossref]

34. Johansson I, Hallmans G, Wikman A, Biessy C, Riboli E, et al. (2002) Validation and calibration of food-frequency questionnaire measurements in the Northern Sweden Health and Disease cohort. Public Health Nutr 5: 487-496. [Crossref]

35. Erkkola M, Karppinen M, Javanainen J, Rasanen L, Knip M, et al. (2001) Validity and reproducibility of a food frequency questionnaire for pregnant Finnish women. $\mathrm{Am} \mathrm{J}$ Epidemiol 154: 466-476.

36. Shu XO, Yang G, Jin F, Liu D, Kushi L, et al. (2004) Validity and reproducibility of the food frequency questionnaire used in the Shanghai Women's Health Study. Eur J ClinNutr 58: 17-23. [Crossref]

37. Cade J, Thompson R, Burley V, Warm D (2002) Development, validation and utilisation of food-frequency questionnaires-a review. Public Health Nutr 5: 567-587. [Crossref]

38. Phillips MA (1998) Reproducibility of a School-based Nutrition Monitoring Questionnaire in 4th Grade Elementary School Students [master's thesis], University of Texas School of Public Health

39. Field AE, Peterson KE, Gortmaker SL (1999) Reproducibility and validity of a food frequency questionnaire among fourth to seventh grade inner-city school children: implications of age and day-to-day variation in dietary intake. Public Health Nutr 2 293-300. [Crossref]

40. Michels KB, Welch AA, Luben R, Bingham SA, Day NE (2005) Measurement of fruit and vegetable consumption with diet questionnaires and implications for analyses and interpretation. Am J Epidemiol 161: 987-994. [Crossref]

41. Nelson M (1997) The validation of dietary assessment. In: Margetts BM, Nelson $\mathrm{M}$, editors. Design concepts in nutritional epidemiology. 2nd ed. Oxford: Oxford University Press.

Copyright: (C2015 Gao-Balch YH. This is an open-access article distributed under the terms of the Creative Commons Attribution License, which permits unrestricted use, distribution, and reproduction in any medium, provided the original author and source are credited. 